\title{
PROPERTY PRICE MODELLING, MARKET SEGMENTATION AND SUBMARKET CLASSIFICATIONS: A REVIEW
}

\author{
Hamza Usman \\ Universiti Tun Hussein Onn Malaysia; \\ Abubakar Tafawa Balewa University Bauchi, Nigeria \\ e-mail:hamzeeusm@gmail.com \\ Mohd Lizam \\ Faculty of Technology Management and Business, \\ Universiti Tun Hussein Onn Malaysia \\ e-mail:lizam@uthm.edu.my \\ Muhammad Usman Adekunle \\ Department of Estate Management and Valuation, \\ Abubakar Tafawa Balewa University Bauchi, Nigeria \\ e-mail:babaucy@gmail.com
}

\begin{abstract}
Accurate pricing of the property market is necessary to ensure effective and efficient decision making. Property price is typically modelled using the hedonic price model (HPM). This approach was found to exhibit aggregation bias due to its assumption that the coefficient estimate is constant and fails to consider variation in location. The aggregation bias is minimized by segmenting the property market into submarkets that are distinctly homogeneous within their submarket and heterogeneous across other submarkets. Although such segmentation was found to improve the prediction accuracy of HPM, there appear to be conflicting findings regarding what constitutes a submarket and how the submarkets are to be driven. This paper therefore reviews relevant literature on the subject matter. It was found that, initially, submarkets were delineated based on a priori classification of the property market into predefined boundaries. The method was challenged to be arbitrary and an empirically statistical data-driven property submarket classification was advocated. Based on the review, there is no consensus on the superiority of either of the methods over the another; a combination of the two methods can serve as a means of validating the effectiveness of property segmentation procedures for more accurate property price prediction.
\end{abstract}

Key words: Property Market Segmentation, Hedonic Price Modelling, Submarkets, Property Market.

JEL Classification: D49, R30.

Citation: Usman, H., Lizam, M., Adekunle, M.U. (2020). Property price modelling, market segmentation and submarket classifications: a review. Real Estate Management and Valuation, 28(3), 2435.

DOI: https://doi.org/10.1515/remav-2020-0021

\section{Introduction}

Accurate pricing of properties is a prerequisite for the sustainable growth and development of economies. Numerous economic activities, such as mortgage lending, taxations, investment, merger, auctions, balance sheet, and buying and selling of properties depend on property prices (Pryce, 2013; 
Abidoye \& Chan 2017; Mayer, et al., 2019). Inaccurate property prices and indexes may result in inaccurate investment decisions that are deleterious to the business entity concerned (Chen, et al. 2009; Manganelli, et al., 2015; Feng \& Jones, 2016). Properties are traditionally appraised using conventional valuation techniques (Aliyu, et al. 2018). However, with sophistication in technology, the need to appraise a large number of properties, to automate the appraisal process and to reduce time and cost, mass appraisal techniques was developed based on the hedonic model (Abdullahi, et al., 2018; Malinowski, et al., 2018). The hedonic model was championed by the seminal work of ROSEN (1974) on hedonic prices and implicit markets. Hedonic price models were used afterwards to estimate property prices (Kauko, 2003; Baudry \& Maslianskaia-Pautrel, 2015; Fotheringham \& Park, 2018; Mora-Garcia, et al., 2019). Relying on the earlier concentric theory, the access and space model which views property as a homogeneous good whose price is inversely related to the central business district, the hedonic function modelled property price as the summation of the implicit prices of its structural characteristics, neighbourhood features and location (Chen, et al., 2009; Fonnesbech-Wulf, et al., 2011). The hedonic function is developed based on the assumption of spatial equilibrium of supply and demand for the various property characteristics, which are assumed to have a fixed effect on property prices across space (Feng \& Jones, 2016). However, this basic assumption of equilibrium price for each characteristic and homogeneous market has been criticized, especially when modelling using regional data (Dale-Johnson, 1982; Bourassa, et al., 2007; Barreca, et al., 2017).

The use of an aggregated hedonic model in estimating property prices has been criticized due to some reported problems, such as spatial autocorrelation and heteroscedasticity. The assumption that properties are spatially independent is less likely to be valid in hedonic price function, as the residuals of house price have been found to show spatial dependence even when location effects are modelled (Bourassa, et al., 2007). The discriminate and unobservable location attributes of property makes its price dependent on the near property price, resulting in correlated residuals. Spatial autocorrelation occurs because properties within a given neighborhood for the most part share both similar characteristics and neighborhood amenities, which partly determine the neighbourhood property price (Goodman \& Thibodeau, 1998; Thibodeau, 2003; Bourassa, et al., 2007). The presence of spatial autocorrelation makes price estimation in a hedonic model inefficient and causes a problem in property price modelling ( $\mathrm{Tu}$, et al., 2007; Manganelli, et al., 2015; $\mathrm{Wu}$, et al., 2018). Property market segmentation dis-aggravates the problems of an aggregated hedonic model (Watkins, 1999; Bourassa, et al., 2007; Pryce, 2013; Keskin \& Watkins, 2016).

Properties are heterogeneous and unique at least in terms of their location. Properties are also differentiated by their structural, physical and neighbourhood characteristics (Islam \& Asami, 2010). These differential characterizations of a property require a holistic consideration of the distinct components of the property through market segmentation (Keskin, 2008; Gabrielli, et al., 2017; Warren, et al., 2017). Market segmentation is the delineation or disaggregation of the property market into uniquely distinct submarkets, which are homogeneous within and heterogeneous among the submarkets. Several studies have shown that market segmentation significantly improves the accuracy of property price prediction (Bourassa, et al., 2007; Goodman \& Thibodeau, 2007; Manganelli, et al., 2014; Shi, et al., 2015; Amédée-Manesme, et al., 2017).

Over the decades, different methods were developed to determine property submarkets. These methods are based on a priori classification of the property markets across a predefined boundary as well as on empirically data-driven submarkets, using numerous statistical techniques, such as factor analysis, clustering, and spatial econometrics (Bourassa, et al., 2007; Nappi-Choulet \& Maury, 2009; Beracha, et al., 2018; Calka, 2019). Although there is a consensus in previous studies on the improvement of property prediction accuracy through market segmentation, this cannot be said of the strategies and methods of classifying and deriving property submarkets. This study therefore presents an overview of property market segmentation, the methods used in delimiting submarkets and a comparison of the different methods of property market segmentation. The subsequent sections of the paper focus on property market segmentation, submarket classification strategies, a comparison between the classifications and, finally, the conclusion.

\section{Property Market Segmentation}

Property market segmentation is the delineation or disaggregation of the property market into uniquely distinct submarkets, which are homogeneous within and heterogeneous among the 
submarkets. Early studies on property segmentation, such as that of Palm (1978), considered a property segment or submarket to be the interaction of sellers and buyers with different priceattribute appraisals. Tu et al. (2007) narrated that various contributors in the housing market literature in the past decades considered the housing market to be set of distinctive but interrelated submarkets. The prices of the distinctive components in the hedonic price function across the submarkets are significantly different. Submarkets are technically clusters of related attributes, which are apparently distinct from other clusters (Burhan 2014). The definition of a housing submarket offered by Goodman and Thibodeau (1998) is distinct but related to the other definitions. They defined a housing submarket as "geographic areas where (1) the price of housing (per unit of service) is constant and (2) individual housing characteristics are available for purchase". This definition implies that the benefits derived from units of each housing service provided by the different housing attributes (structural, physical, neighborhood and locational) are substantially the same within the submarket, but distinct across submarkets.

Inoue et al. (2018) pointed out that a property market is geographically segmented so that the attributes' price of the property is different for each submarket. The identification of the right segmentation is necessary for accurate property pricing. Thus, the importance of property market segmentation in price modelling cannot be overemphasized (Keskin \& Watkins, 2017). Incorporation of market segmentation into the pricing model helps to avoid aggregation bias. Aggregation bias occurs as a result of integrating homogeneously distinct submarkets into a "forced" whole market, which leads to inaccurate parameter estimates and poor model fit. Segmenting the property market therefore leads to better accuracy of the property price structure. Such characterization of the market reveals the structure of the urban property market, captures price movement in different locations, and substantially improves the prediction of property price, therefore making the price forecast more reliable and accurate (Burhan, 2014; Goodman and Thibodeau 2003; Pryce, 2013; Gabrielli, et al., 2017).

\section{Property Submarket Classification}

Property segmentation has evoked the interest of many researchers over the past decades. However, over this period, no single generally accepted means of segmenting the property market into submarkets that are homogenous within and heterogeneous among the submarkets has been devised . The characterization of the property market is broadly done into two classifications. The two classifications are segmentation-based on a priori knowledge of the submarkets and data-driven submarket classification (Gabrielli, et al., 2017; Hwang, 2015; Levkovich, et al., 2018; Ling \& Hui, 2013). Within the a priori classification, the property market is classified based on different criteria. For instance, Palm (1978) segmented the housing market based on the San Francisco real estate board jurisdiction. Other studies segmented the housing markets into submarkets based on socio-economic characteristics (Farber, 1986), neighborhood quality (Keskin, 2008), political districts, wards, stations (Inoue, et al., 2018; Ling \& Hui, 2013), the quality of public education, census tract and zip code districts (Goodman \& Thibodeau, 2003), property types (Watkins, 1999), historic district designation (Warren, et al., 2017) and land use zoning regulation (Levkovich, et al., 2018).

However, the arbitrary segmentation of the property market based on a priori criteria has been challenged (Ling \& Hui, 2013; Watkins, 1999). To overcome the arbitrariness of a priori segmentation, several studies allowed the data to empirically segment the housing market using a different methodology. For instance, a data-driven submarket could cluster the market based on property type (Watkins, 1999), structural characteristics (Gabrielli, et al., 2017), neighborhood characteristics (Tu, et al., 2007), spatial characteristics or a combination of such characteristics (Burhan, 2014), empirically using numerous statistical tools.

\subsection{A Priori Classification of the Property Submarket}

The a priori classification of the property submarket is the delineation of the property market into predefined boundaries. Prior studies show that the basis of such delineation is mostly based on high school districts, expert defined areas, administrative jurisdictions, postal codes, zip code areas or any other ad hoc procedure (Bourassa, et al., 2007; Chen, et al., 2009; Qu, et al., 2017). Several property market segmentation studies employed these ad hoc procedures in delineating property submarkets. As far back as the last four decades, Palm (1978) segmented the housing market spatially using the neighborhood of San Francisco based on the real estate board's jurisdiction, racial-ethnic composition of the neighborhood, and the average house price of the neighborhoods to determine the 
neighborhood determinants of housing price. The study found that submarket models based on the board of realtor's segmentation are superior to the other bases of segmentation in explaining the variance $\left(R^{2}\right)$ in price change. This finding is validated by Chen et al. (2009), who found that unless the data drive submarkets are nested in administrative boundaries, classification based on realtors' delineation performs better than other methods of segmenting the property market.

On the other hand, Farber (1986) segmented the housing market based on the presence of group homes for mentally retarded persons and the emotionally disturbed. He analyzed whether the presence of such homes has a significant effect on the surrounding residential neighborhood housing price. The study was based on the assumption that "effects of human service facilities will vary with the submarkets in which they are opened". Using transaction data, the housing market was found to be segmented based on the socioeconomic status of the neighborhood. This finding may be related to the fact that socio-demographic factors have tendency of affecting the spatial structure of the property market (Salvati, et al., 2019).

Property submarkets are also delineated based on politically defined geographic boundaries. For instance, Ling and Hui (2013) examined the performance of housing submarkets in Hangzhou city of China during the boom period of 1998-2009 using a priori classification to segment the Hangzhou city into five geographical areas as the housing submarkets. They found that the structure of the housing market is not consistent across the submarkets. However, the relocation pattern, coupled with the trends in housing development, can explain the evolution of a submarket structure to some degree. This may also be because of the imbalance within the political boundaries and the state of transport infrastructure in the submarkets (Tsai, 2018). Thibodeau (2003) examined the accuracy of alternative housing market segmentations in predicting property price in Dallas. First, he modelled the Dallas housing market as a single mono-centric submarket. Secondly, a single model was constructed with dummy variables representing a municipality. Thirdly, each municipality was considered as a submarket and separate models were estimated for each municipality. Fourthly and lastly, 250 submarket price equations were estimated by aggregating adjacent census block groups within the same independent school district. The study found that spatial segmentation improves the accuracy of hedonic price prediction.

In another study, Feng and Jones (2016) compared the performance of housing market delineation based on postcode and census tract using 404,795 house sales in Greater London. Post code geography was considered a geographical entity with spatial contiguity, and the census tract considered social homogeneity and spatial contiguity. The London housing market was nested into five levels in both the postal code geography and census geography. In postal code geography, houses are nested in post codes, post codes nested in the postal sector, the postal sector nested in postal districts and then postal areas. In census geography, the houses were nested into output areas, next in a Lower-layer super output area (LSO), then in a Medium-layer Super Output area (MSO), and finally into London Boroughs. Feng and Jones (2016) found that classification of housing market neighborhoods based on postcode performed better than based on census geography in terms of predictive accuracy, model fit, and accounting for the unexplained variation in the house price. This finding cast a doubt on the suitability of using a hybrid of spatial contiguity and social classification in delineating the housing submarket. Even though the performance of the census tract is lower than that of the postal code, the study of Thibodeau (2003) found that disaggregating the housing market based on the census tract improves the accuracy of house price prediction in Dallas. Feng and Jones (2016) argued that different definitions of a neighborhood, the methods used, the data, and the measures of the model's performance contributed to inconsistencies in the housing market segmentation.

Research into the commercial property market was conducted by Nappi-Choulet and Maury (2009) to test for the presence of spatiotemporal heterogeneity in a hedonic model of office transaction prices for central Paris and its immediate suburbs. The paper concluded that there is significant spatial heterogeneity and dependence in the Paris office market. The paper shows that the autoregressive parameter is overestimated if the influence of spatial effects is not controlled. This finding was championed by Tu et al. (2004) who opine that the disaggregate office price index for the submarket is better than the aggregated index. However, while Nappi-Choulet and Maury (2009) used location dummies and estimated different equations for different submarkets, Tu et al. (2004) did not.

Bourassa et al. (2007) compared the performance of spatial statistical methods with traditional OLS methods in a mass appraisal context. The performance was evaluated using a sample of 4,880 


\section{S sciendo}

residential sales in Auckland, New Zealand. $80 \%$ of the sample was used for observation and the remaining $20 \%$ was used as an "Out of Sample" for prediction. A comparison was made using geostatistical models of exponential and spherical variograms, lattice models of Simultaneous Autoregressive (SAR) and Conditional Autoregressive (CAR), and the OLS model. Each of these models was adjusted using submarket dummy variables based on the valuers' defined boundaries. The results revealed that geostatistical models perform better than OLS. The proportion of price predictions within 10 percent of sales prices for the OLS model without a submarket dummy variable was 39.8 percent. The geostatistical models' prediction within 10 percent of the sales prices was 44 percent. Similarly, based on absolute error statistics with submarket dummy variables adjustment, the OLS performs marginally worse than geostatistical models. The CAR and SAR, however, performed poorly. After comparing the submarket adjusted OLS and the geostatistical models without submarket dummy variables, it was concluded that the OLS models based on geographical segmentation by appraisers perform better than the spatial models in terms of house price prediction accuracy. This conclusion is, however, contrary to some other research (Calka, 2019; Nappi-Choulet \& Maury, 2009; Tu, et al., 2004, 2007).

\subsection{Empirical Data-Driven Submarket Classification}

Proponents of a data-driven property submarket challenged the veracity of the a priori driven property submarket, which may not be effective in clustering similar properties because the delineation is limited based on only major geographical consideration (Shi, et al., 2015). Property buyers do not necessarily constrain their search of houses to only "spatially contagious areas". Restricting the submarket to only spatially contagious areas may not capture the buyers' behaviour and preferences for property characteristics (Goodman \& Thibodeau, 2003, 2007; Shi, et al., 2015). Following the works of Schnare, Struyk (1976) and Palm (1978); Dale-Johnson (1982) questioned the arbitrariness of the ad hoc classifications and subsequently used data to empirically derive housing market price equilibria using Q-factor analysis to group the housing market into 13 limited submarkets. He argued that the a priori classification of the housing market merely shows segmentation exists, but did not address the complexity of the process. Using F-statistics (Chow test) to test the similarity of the disaggregated hedonic price model of the 13 determined submarkets, the existence of market segmentation was confirmed. Afterwards, several market segmentation studies were conducted using statistically driven methods. Using Principal Component Analysis (PCA), Watkins (1999) identified the distinct structurally differentiated market segments by identifying the most common components in the housing bundle. Individual separate hedonic equations were estimated for the identified submarkets. The CHOW test was employed to test if there is a significant difference between the submarket models. After establishing the existence of the submarkets, the weighted standard error was computed and compared with the standard error of the aggregated model to compare the accuracy of the models in house price prediction. The submarket models performed better than the aggregated model.

The use of PCA is extended by the addition of cluster analysis in the identification of the property submarket. Various studies used various forms of cluster analysis such as K-means, Fuzzy C-mean, hard clustering etc. For instance, Burhan (2014) explores the spatial mechanism of the hedonic function in defining the Johor housing market. In constructing the housing submarket, Principal Component Analysis (PCA) and later cluster analysis were employed. The methods were used to classify the housing market using empirical data instead of a priori segmentation. The PCA included the structural elements of the housing units based on which a reduced set of orthogonal factors (components) were extracted. The significant factors were retained for cluster analysis using the Kmeans method employing Euclidean distance between centroids. Homogeneous features were found in each of the derived clusters with some overlapping in the locational component which called for further analysis with the addition of spatial dependence. Employing GIS and spatial analytical tools, the study found that housing market dynamics are better captured by the combined structural and spatial housing attributes effects. The contained clustering method was also used by Zhang et al. (2019) to identify heterogeneity in the housing market in the underlying urban structure.

An "innovative" clustering using Fuzzy C-Mean (FCM) was employed by Shi et al. (2015) in housing market segmentation. Traditional Multiple Regression Analysis (MRA) and Adaptive Neural Fuzzy Inference System (ANFIS) were used to test the predictive accuracy of the disaggregated models. Based on FCM analysis, 10 residential property clusters were obtained. Floor size, building 
date and basement size were the three variables of property characteristics used for the cluster analysis. The other property characteristics variables were used for model building and price prediction. A Mean Price Comparable (MPC) was added to the models after the clustering. The result found that, although the clustering method used in the analysis and the inclusion of MPC improved the result, the traditional hedonic pricing model for the clusters has higher predictive accuracy than the Adaptive Neural Fuzzy Inference System because it yielded much lower errors using Root Mean Squared Error (RMSE), Mean Absolute Error (MAE) and Mean Absolute Percentage Error (MAPE). The work concluded that market segmentation improved the accuracy of price prediction by using both the traditional MRA and the ANFIS.

A combination of hard clustering and fuzzy analysis was used by Gabrielli et al. (2017) to empirically use data to study the gap and overlap in the urban housing market. The study segmented the housing market into 6 groups through clustering. Unlike Watkins (1999), the study did not utilize the PCA prior to clustering. Gabrielli et al. (2017) used both the hierarchical and non-hierarchical cluster analysis approaches to identify different groups in the real estate market. The hard clustering and fuzzy clustering analysis shows that the housing market is segmented with gaps and overlaps among the segments. An entirely different method, generalised fused LASSO, was used by Inoue et al. (2018) to investigate the geographical segmentation of apartment properties in the Tokyo metropolitan area. The research found that rental apartments are segmented by rail stations, wards, and neighbourhoods. The study argued that the geographical segmentation displays hierarchical patterns.

More recently, spatial econometric analyses are utilized in segmenting the property market. For instance, Tu et al. (2007) used the spatial autocorrelation structure of the market wide hedonic model for their analysis. The housing units were clustered into groups based on their spatial autocorrelations. The clusters were aggregated into submarkets. They found new and more specifically defined submarkets for private condominiums in Singapore. The findings of the research is in agreement to that of Watkins (1999), at least to certain extent. While Watkins (1999) found the housing submarket to be based on structural characteristics and housing types, Tu et al. (2007) found submarkets to be based on market segmentation clusters. The similarity of findings cannot be unrelated to the methods employed in the studies. Extracting property components and clustering them leave the possibility of the spatial dependence of the property unexplained. Based on their findings, they challenged the use of a priori segmentation based on conventional administrative or any pre-defined boundaries used in the previous housing submarket literatures.

Similarly, Massimo et al. (2018) tested the robustness of geographically weighted regression in identifying the homogeneity of an area and the effect of spatial location on property prices. An alternative methodology was used by Kauko et al. (2002) to determine the structure of housing segmentation in Helsinki, Finland. Using neural network modelling, a Self-Organising Map (SOM) and the Learning Vector Quantisation (LVQ), they found that the housing submarket is determined by relative location and housing type, with the price level exerting a smaller influence. However, they noticed some shortcomings of the method in segmenting the housing market and advocated its use only with absolute care. Using spatial econometric analysis, Fonnesbech-Wulf et al. (2011) checked the presence of spatial heterogeneity and dependence in property prices in relation to modelling the effect of (dis)amenities and other property features. Data from 2,918 single family house sales in a Danish municipality was used to test the proposition. The results showed the presence of spatial heterogeneity and dependence in the data set. The generalized spatial model performed better than the SAR, SEM and OLS (in the sequential order of importance) in predicting housing prices in the Danish Municipality. This finding confirms the findings of (Kim \& Zhang, 2005), who found superior performance of spatial models over the OLS in house price estimation.

Kim and Zhang (2005) also tested if the impact of a transit station on commercial values is the same across the metropolis real estate market or if it varies across the submarkets based on spatial structure or development densities of the station areas. Using appraisal data of 732 commercial land values in Seoul, Korea, the research employed the Ordinary Least Squares (OLS) method, Spatial Autoregressive (SAR) method, the Spatial Error Model (SEM) and general Spatial Autocorrelation (SAC). The results found that the impact of transit train stations on commercial property values vary across submarkets. The study found spatial dependence in commercial property values resulting in the overestimation of the location premium, which causes the statistical inefficiency of the model. The results also show that the spatial econometric models, i.e., SAR, SEM and SAC outperformed the OLS 


\section{S sciendo}

model in predicting commercial property prices. Moreover, incorporating both the spatial lag and error term in the regression equation was found to increase the goodness of fit of the equations. These results are supported by those of Tu et al. (2004), Nappi-Choulet and Maury (2009).

\subsection{Hybrid Submarket Classification}

The use of either a priori classifications or data-driven segmentation of the property market have been shown to exhibit different findings. Other studies combined the methods either individually or were nested into each other. For instance, using nested criteria, Goodman and Thibodeau (1998) examine housing market segmentation within metropolitan Dallas. The paper modelled housing submarkets with hedonic price models using a method that decomposes submarket and housing characteristic components called the hierarchical model. The results of the study show that housing submarkets are clustered according to the quality of public schools and concluded that hierarchical models provide a useful framework for delineating housing submarkets. The method was recommended to be replicated in other studies or cases to verify its efficacy. Based on this recommendation, Goodman and Thibodeau (2003) employed a hierarchical hedonic model to investigate the improvement of hedonic pricing prediction by spatially disaggregating the submarkets. The previous study was extended to examine prediction accuracy. Accordingly, four delineation alternatives, including a hedonic model with spatial aggregation, submarket delineation using zip code districts, submarket delineation by census tract, and identification of the housing submarket using the Goodman-Thibodeau (GT) technique, were employed. They confirm the framework of hierarchical hedonic modelling in housing market segmentation and found that spatial disaggregation improves the accuracy of hedonic housing price prediction. This finding also confirms that of Watkins (1999), who found that the (weighted) standard error of the segmented model is significantly lower than that of the market-wide model, which signifies improved accuracy of the disaggregated models based on the submarket.

Other studies compare the individual performance of the submarket segmentation methods. For instance, Chen et al. (2009) evaluated models forecasting accuracy under different submarket classification assumptions. Seven submarket classifications were used for the analysis. K-means clustering and two-step procedure clustering were data-driven statistical clustering used for the modelling. Three of the classifications were based on predetermined geographical segmentation. These include high school districts, expert-defined submarkets based on realtors' demarcation, and local government jurisdiction. A hybrid of statistical clustering and geographical segmentation based on local government jurisdiction was also used. Finally the authors used random segmentation based on an arbitrary $4 X 4$ mile grid of the housing market. They found that a non-segmented market model performed poorly in relation to the segmented models; the a priori models performed better than the empirical data-driven statistical clustering models. The results also found that the hybrid of the a priori and data-driven market segmentation was the most efficient price forecasting model followed by the expert-defined submarket model, local government jurisdiction, high school district, K-mean clustering, and two-step clustering. The least efficient model is based on arbitrary segmentation of the housing market, although it nevertheless performed better than the no-segmentation model. The superiority of the a priori delineation over a data-driven submarket is contrary to the findings of Tu et al. (2007), which challenged the use of a priori segmentation. The findings may be close to those of Bourassa et al. (2007), who concluded that the OLS models based on geographical segmentation by appraisers perform better than the data-driven spatial models in terms of house price prediction accuracy.

\section{Comparison of Submarket Delineations}

The aim of delineating a property market into submarkets is to improve the accuracy of the price prediction irrespective of the method of segmentation employed. It is the employment of different means to achieve a common goal. However, the point of contention is whether the selected classification method is the best method to maximize accuracy at a given circumstance. This is because different situations may require a different approach, and the motive behind the construction of a submarket strongly affects delineation ( $\mathrm{Tu}$, et al., 2007). For instance, Malinowski et al. (2018) concluded that a priori classification based on administrative cadastral zones and expert zones perform better if the partitions are in accordance with natural boundaries and that data-driven delineations are better used in homogeneous market segmentation. This may thus be related to the motive behind market segmentation. 
Each method of submarket delineation has its perceived strengths and weakness. A priori classification of the property market has been criticized to be non-scientific and arbitrary (Chen, et al., 2009; Dale-Johnson, 1982; Wu, et al., 2018). The method was criticized because the selection of a particular classification either based on administrative boundaries, expert defined boundaries, school districts, zip codes, postal codes or other ad hoc criteria could not reveal homogeneity in the submarket, seeing as how property prices are not differentiated by only geographic division but also by its other characteristics, such as the structural characteristics (Goodman \& Thibodeau, 2003; Gavu, et al., 2019). Besides the expert-defined submarket, whose primary purpose is property pricing, other delineations are primarily used for purposes such as elections, mail services or school enrolment, which may not be related to the property market pattern. Thus, property market homogeneity within such submarkets may not necessarily exist (Bourassa, et al., 2007; Feng \& Jones, 2016). Heterogeneity within the submarket may lead to aggregation bias, which jeopardizes optimal prediction accuracy (Chen, et al., 2009; Watkins, 1999). This may be the reason why an administratively-defined boundary was found to be less effective in submarket delineation (Shi, et al., 2015).

The frequent use of the a priori delineation in the property market may be related to the method's convenience, straightforwardness and cost effectiveness (Feng, Jones 2016). Several studies conducted using the a priori classification found the method to be worthy, as it improves the prediction accuracy of property prices. Some studies concluded that the a priori delineation of the property market performs better than data-driven submarket models (Chen \& Li, 2017; Malinowski, et al., 2018). However, most of the studies noting the superior performance of a priori segmentation were based on expert delineation of the property market. Realtors' delineation is based on expert experience of the structural, neighborhood and locational characteristics of the property, and how the property buyers and sellers behave over time, which makes the market as homogeneous as possible. This may not be generalizable because other studies questioned the accuracy of a priori delineation and opted for the empirically data-driven submarket classification (Calka, 2019; Salvati, et al., 2019; Wu, et al., 2018).

Despite the strength of the data-driven method in modelling the submarket rather than imposing it arbitrarily, this method was also subjected to criticism, prompting improvements in the methods of classification. For instance earlier works used factor analysis and K-mean clustering to delineate a property submarket (Dale-Johnson, 1982; Watkins, 1999). Several other methods were used afterwards, such as fuzzy clustering (Malinowski, et al., 2018; Shi, et al., 2015), hard clustering (Gabrielli, et al., 2017), generalized fused LASSO (Inoue, et al., 2018), and, lately, spatial econometrics (Fonnesbech-Wulf, et al., 2011; Massimo, et al., 2019). Although the data-driven method proves to be powerful and robust, the property market was shown to be hierarchical (Burhan, 2014; Goodman \& Thibodeau, 1998, 2003). Nesting the data-driven submarkets into a priori boundaries was shown to perform better than the two methods individually (Chen, et al., 2009; Goodman \& Thibodeau 2003).

The submarket delineation methods were all shown to be effective in certain studies. The findings from different studies seem inconsistent. To overcome this inconsistency, Gavu and Owusu-Ansah (2019) recommended the use of alternative delineation methods, comparing the results afterwards. Finally, to achieve the optimal precision desired by property market segmentation, the submarkets, demarcation criteria, definitions, and statistical methods must be carefully defined and conceptualized. The property market segmentation classification is outlined in Fig. 1.

\section{Conclusion}

The need to accurately predict property prices has been advocated for economic reasons. Property price modelling using Hedonic Price Modelling (HPM) has taken the center stage in property pricing deliberation. While it provides the base for modelling price, several issues, such as aggregation bias, have been raised in connection with its efficacy under certain circumstances. To solve the problem of aggregation bias in the hedonic price model, the housing market is segmented into uniquely distinct submarkets, which are homogeneous within and heterogeneous among the submarkets. Such disintegration of the property market into submarkets is shown to have improved property pricing significantly. Although property segmentation improves the accuracy of price prediction, defining what constitutes a submarket and how to identify or determine one has been an issue of long and sustained debate. Earlier studies of property market segmentation used a priori knowledge of predefined boundaries based on geography, social-economic characteristics, race, or any other ad hoc definitions to delineate the property market into segments. The a priori segmentation was later 
criticized due to its arbitrariness, and the use of statistically data-driven property submarkets was advocated. Others argued that a property market is nested, and neither of the methods can adequately capture the complexity of the housing market, therefore advocating the combination of methods in segmenting the property market. The overview of the literature shows that market segmentation generally improves property price prediction. All of the methods of delineating the property market into submarkets have been found to improve prediction accuracy, though with different findings regarding the superiority of one over the other. Generally, there is no consensus on the superiority of any of the methods over the others; the combination of two methods can therefore serve as a means of validating the effectiveness of property segmentation procedures for more accurate property price prediction. This research is limited to a general overview of property market segmentation and its methods, and thus, is not a systematic review. The present research therefore recommends further studies that systematically synthesize literature on property market segmentation in the form of metaanalysis.

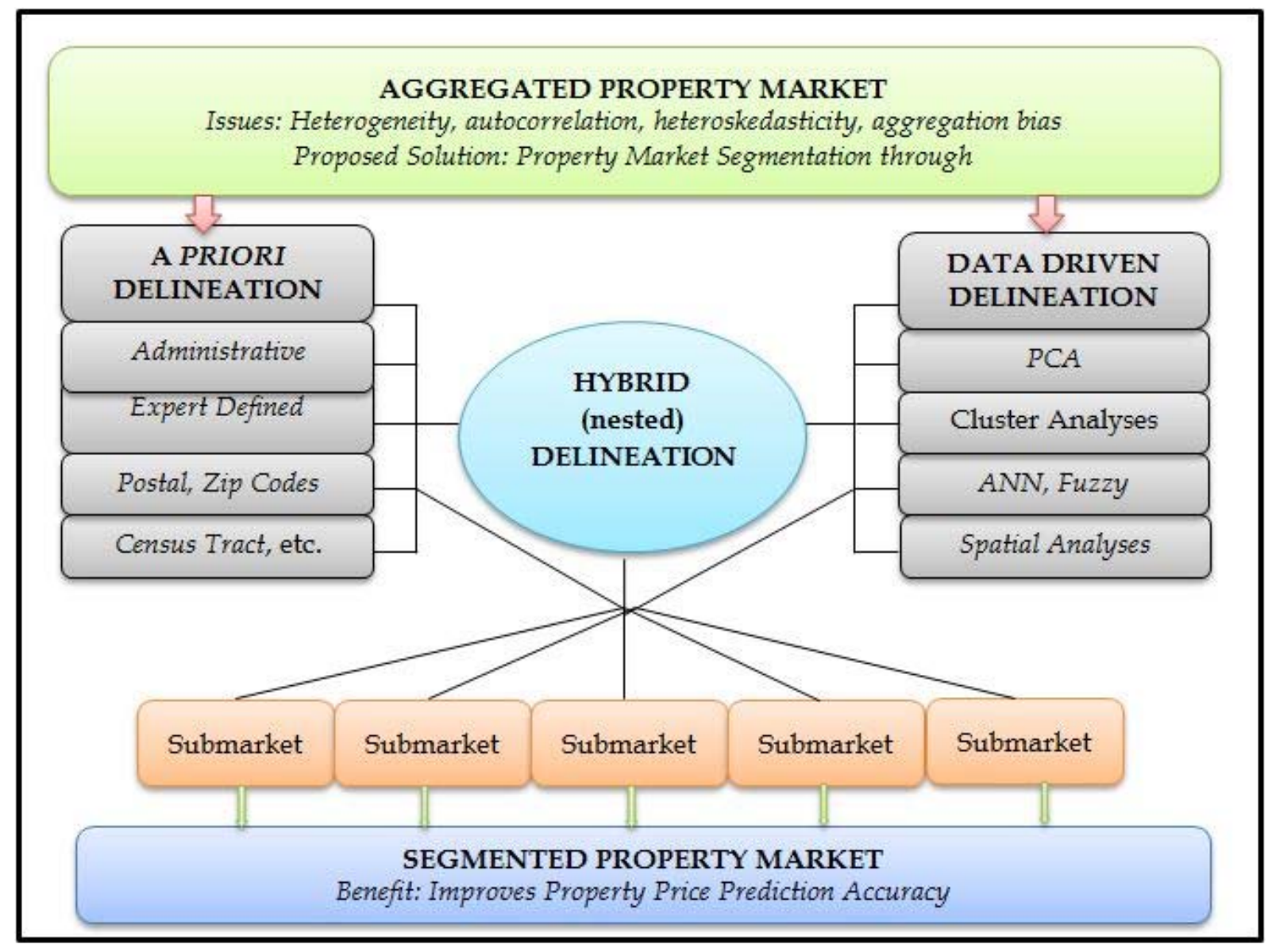

Fig. 1. The figure is used to show the various classification methods and their interaction. It does not, however, exhaust all classification methods, and is more an example of the most commonly used methods of property market segmentation. Source: own study.

\section{Acknowledgement:}

The authors would like to thank the Ministry of Education of Malaysia for supporting this research under the Fundamental Research Grant Scheme Vot No. FRGS/1/2018/SS08/UTHM/02/1 and partially sponsored by Universiti Tun Hussein Onn Malaysia.

\section{References}

Abdullahi, A., Usman, H., \& Ibrahim, I. (2018). Determining house price for mass appraisal using multiple regression analysis modeling in Kaduna North, Nigeria. ATBU Journal of Environmental Technology, 11(1), 26-40. 
Abidoye, R. B., \& Chan, A. P. C. (2017). Critical review of hedonic pricing model application in property price appraisal: A case of Nigeria. International Journal of Sustainable Built Environment, 6(1), 250-259. Advance online publication. https://doi.org/10.1016/j.ijsbe.2017.02.007

Aliyu, B. A., Sani, H., Usman, H., \& Muhammad, H. (2018). Ranking the Causative Factors of Mortgage Valuation Inaccuracy in Kaduna Metroplois. Real Estate Management and Valuation, 26(3), 71-81. https:// doi.org/10.2478/remav-2018-0026

Amédée-Manesme, C. O., Baroni, M., Barthélémy, F., \& Des Rosiers, F. (2017). Market heterogeneity and the determinants of Paris apartment prices: A quantile regression approach. Urban Studies (Edinburgh, Scotland), 54(14), 3260-3280. https://doi.org/10.1177/0042098016665955

Barreca, A., Curto, R., \& Rolando, D. (2017). Assessing Social and Territorial Vulnerability on Real Estate Submarkets. Buildings, 7(4), 94. https://doi.org/10.3390/buildings7040094

Baudry, M., \& Maslianskaia-Pautrel, M. (2015). Revisiting the hedonic price method in the presence of market segmentation. Environmental Economics and Policy Studies. Springer Japan., https:// doi.org/10.1007/s10018-015-0122-5

Beracha, E., Hardin, W. G. III, \& Skiba, H. M. (2018). Real Estate Market Segmentation: Hotels as Exemplar. The Journal of Real Estate Finance and Economics, 56, 252-273. https:// doi.org/10.1007/s11146-017-9598-z

Bourassa, S. C., Cantoni, E., \& Hoesli, M. (2007). Spatial Dependence, Housing Submarkets, and House Price Prediction. The Journal of Real Estate Finance and Economics, 35, 143-160. https:// doi.org/10.1007/s11146-007-9036-8

Burhan, B. B. (2014) Spatial Mechanism of Hedonic Price Functions For Housing Submarket Analysis. Unpublished Ph.D. Thesis: Saga University, Japan.

Calka, B. (2019). Estimating Residential Property Values on the Basis of Clustering and Geostatistics. https://doi.org/10.3390/geosciences9030143.

Chen, W. Y., \& Li, X. (2017). Cumulative impacts of polluted urban streams on property values: A 3-D spatial hedonic model at the micro-neighborhood level. Landscape and Urban Planning, 162, 1-12. https:/ / doi.org/10.1016/j.landurbplan.2017.01.012

Chen, Z., Cho, S., Poudyal, N., \& Roberts, R. K. (2009). Forecasting Housing Prices under Different Market Segmentation Assumptions. Urban Studies (Edinburgh, Scotland), 46(1), 167-187. https://doi.org/10.1177/0042098008098641

Dale-Johnson, D. (1982). An Alternative Approach to Housing Market Segmentation Using Hedonic Price Data. Journal of Urban Economics, 11, 311-332. https:// doi.org/10.1016/0094-1190(82)90078-X

Farber, S. (1986). Market Segmentation and the Effects on Group Homes for the Handicapped on Residential Property Values. Urban Studies (Edinburgh, Scotland), 23, 519-525. https://doi.org/10.1080/00420988620080801

Feng, Y., \& Jones, K. (2016). Comparing two neighbourhood classifications: a multilevel analysis of London property price 2011-2014. Pacific Rim Real Estate Conference, Queensland, January.

Fonnesbech-Wulf, A., Termansen, M., Fuglsang, M., Smart, J., Ladenburg, J., Hasler, B. (2011). Welfare impacts of landscape dis-amenities: comparative hedonic approaches. Conference of the Danish Environmental Economic Council.

Fotheringham, A. S., \& Park, B. (2018). Localized spatiotemporal effects in the determinants of property prices: A case study of Seoul. Applied Spatial Analysis and Policy, 11(3), 581-598. https:// doi.org/10.1007/s12061-017-9232-8

Gabrielli, L., Giuffrida, S., \& Trovato, M. R. (2017). Gaps and Overlaps of Urban Housing Sub-market: Hard Clustering and Fuzzy Clustering Approaches, in Appraisal: From theory to practice, pp. 203-219. doi: 10.1007/978-3-319-49676-4

Gavu, E. K., \& Owusu-Ansah, A. (2019). Empirical analysis of residential submarket conceptualisation in Ghana. International Journal of Housing Markets and Analysis, 12(4), 763-787. https:// doi.org/10.1108/IJHMA-10-2018-0080

Goodman, A. C., \& Thibodeau, T. G. (1998). Housing Market Segmentation. Journal of Housing Economics, 7, 121-143. https://doi.org/10.1006/jhec.1998.0229

Goodman, A. C., \& Thibodeau, T. G. (2003). Housing market segmentation and hedonic prediction accuracy. Journal of Housing Economics, 12(3), 181-201. Advance online publication. https://doi.org/10.1016/S1051-1377(03)00031-7 
Goodman, A. C., \& Thibodeau, T. G. (2007). The Spatial Proximity of Metropolitan Area Housing Submarkets. Real Estate Economics, 35(2), 209-232. https://doi.org/10.1111/j.15406229.2007.00188.x

Hwang, S. (2015). Residential Segregation, Housing Submarkets, and Spatial Analysis: St. Louis and Cincinnati as a Case Study. Housing Policy Debate, 25(1), 91-115. https://doi.org/10.1080/10511482.2014.934703

Inoue, R., Ishiyama, R., \& Sugiura, A. (2018). Identification of Geographical Segmentation of the Rental Apartment Market in the Tokyo Metropolitan Area, in 10th International Conference on Geographic Information Science (GISience 2018), Germany, 1-6.

Islam, K. S., \& Asami, Y. (2010). Housing Market Segmentation: A Review. Review of Urban and Regional Development Studies, 21(2). Advance online publication. https://doi.org/10.1111/j.1467940X.2009.00161.x

Kauko, T. (2003). Residential property value and locational externalities: On the complementarity and substitutability of approaches. Journal of Property Investment \& Finance, 21(3), 250-270. https://doi.org/10.1108/14635780310481676

Kauko, T., Hooimeijer, P., \& Hakfoort, J. (2002). Capturing Housing Market Segmentation: An Alternative Approach based on Neural Network Modelling. Housing Studies, 17(6), 875-894. https:// doi.org/10.1080/02673030215999

Keskin, B. (2008). Hedonic analysis of price in the istanbul housing market. International Journal of Strategic Property Management, 12(2), 125-138. https://doi.org/10.3846/1648-715X.2008.12.125-138

Keskin, B., \& Watkins, C. (2017). Defining spatial housing submarkets : Exploring the case for expert delineated boundaries. Urban Studies (Edinburgh, Scotland), 54(6), 1446-1462. https:// doi.org/10.1177/0042098015620351

Kim, J., \& Zhang, M. (2005). Determining Transit's Impact on Seoul Commercial Land Values: An Application of Spatial Econometrics. International Real Estate Review, 8(1), 1-26.

Levkovich, O., Rouwendal, J., Brugman, L. (2018). Spatial Planning and Segmentation of the Land Market: The Case of the Netherlands. Land Economics, 94(1), 137-154. https:// doi.org/10.3368/le.94.1.137

Ling, Z., \& Hui, E. C. M. (2013). Structural change in housing submarkets in burgeoning real estate market: A case of Hangzhou, China. Habitat International, 39, 214-223. https:// doi.org/10.1016/j.habitatint.2012.12.006

Malinowski, A., Piwowarczyk, M., Telec, Z., Trawinski, B., Kempa, O., \& Lasota, T. (2018) An Approach to Property Valuation Based on Market Segmentation with Crisp and Fuzzy Clustering. International Conference on Computational Collective Intelligence, 534-548. https:// doi.org/10.1007/978-3-31998443-8_49

Manganelli, B., De Mare, G., \& Nesticò, A. (2015). Using Genetic Algorithms in the Housing Market Analysis. Lecture Notes in Computer Science, 9157, 36-45. https://doi.org/10.1007/978-3-319-214702_3

Manganelli, B., Pontrandolfi, P., Azzato, A., \& Murgante, B. (2014). Using geographically weighted regression for housing market segmentation, International Journal of Business Intelligence and Data Mining (IJBIDM), 9(2), 161-177. https:// doi.org/10.1504/IJBIDM.2014.065100

Massimo, D. E., Del Giudice, V., De Paola, P., Forte, F., Musolino, M., \& Malerba, A. (2018). Geographically Weighted Regression for the Post Carbon City and Real Estate Market Analysis: A Case Study. International Symposium on New Metropolitan Perspectives, 142-149.

Mayer, M., Bourassa, S. C., Hoesli, M., \& Scognamiglio, D. (2019). Estimation and updating methods for hedonic valuation. Journal of European Real Estate Research, 12(1), 134-150. https:// doi.org/10.1108/JERER-08-2018-0035

Mora-Garcia, R. T., Cespedes-Lopez, M. F., Perez-Sanchez, V. R., Marti, P., \& Perez-Sanchez, J. C. (2019). Determinants of the Price of Housing in the Province of Alicante (Spain): Analysis Using Quantile Regression. Sustainability, 11(2), 437. https://doi.org/10.3390/su11020437

Nappi-Choulet Pr, I., \& Maury, T. P. (2009). A Spatiotemporal Autoregressive Price Index for the Paris Office Property Market. Real Estate Economics, 37(2), 305-340. https://doi.org/10.1111/j.15406229.2009.00244.x

Palm, R. (1978). Spatial segmentation of the urban housing market. Economic Geography, 54(3), 210-221. https://doi.org/10.2307/142835 
Pryce, G. (2013). Housing Submarkets and the Lattice of Substitution. Urban Studies (Edinburgh, Scotland), 50(13), 2682-2699. https:// doi.org/10.1177/0042098013482502

Qu, Y., Qu, H., \& Chen, G. (2017). Market segmentation for a leverage revitalization of China's inbound tourism: the case of US leisure tourists. Current Issues in Tourism, 21(6), 646-662. https://doi.org/10.1080/13683500.2016.1264054

Rosen, S. (1974). Hedonic prices and implicit markets: Product differentiation in pure competition. Journal of Political Economy, 82(1), 34-55. https://doi.org/10.1086/260169

Salvati, L., Ciommi, T. M., Serra, P., \& Chelli, F. M. (2019). Land Use Policy Exploring the spatial structure of housing prices under economic expansion and stagnation: The role of sociodemographic factors in metropolitan. Land Use Policy, 81, 143-152. https:// doi.org/10.1016/j.landusepol.2018.10.030

Schnare, A. B., \& Struyk, R. J. (1976). Segmentation in urban housing markets. Journal of Urban Economics, 3(2), 146-166. https:// doi.org/10.1016/0094-1190(76)90050-4

Shi, D., Guan, J., Zurada, J., \& Levitan, A. S. (2015). An Innovative Clustering Approach to Market Segmentation for Improved Price Prediction. Journal of International Technology and Information Management, 24(1), 15-32.

Thibodeau, T. G. (2003). Marking Single-Family Property value to market. Real Estate Economics, 31(1), 1-22. https:// doi.org/10.1111/j.1080-8620.2003.00055.x

Tsai, I. (2018). Housing price convergence, transportation infrastructure and dynamic regional $\begin{array}{llll}\text { population } \quad \text { relocation. Habitat } & \text { International, 79, }\end{array}$ https:// doi.org/10.1016/j.habitatint.2018.07.004

Tu, Y., Sun, H., \& Yu, S. (2007). Spatial Autocorrelations and Urban Housing Market Segmentation. The Journal of Real Estate Finance and Economics, 34, 385-406. https://doi.org/10.1007/s11146-0079015-0

Warren, C. M. J., Elliott, P., \& Staines, J. (2017). The impacts of historic districts on residential property land values in Australia. International Journal of Housing Markets and Analysis, 10(1), 66-80. https:// doi.org/10.1108/IJHMA-02-2016-0015

Watkins, C. (1999). Property valuation and the structure of urban housing markets. Journal of Property Investment \& Finance, 17(2), 157-175. https:/ / doi.org/10.1108/14635789910258543

$\mathrm{Wu}, \mathrm{C} .$, Ye, X., Ren, F., \& Du, Q. (2018). Modified data-driven framework for housing market segmentation Modified data-driven framework for housing market segmentation. Journal of Urban Planning and Development, 144(4), 04018036. Advance online publication. https://doi.org/10.1061/(ASCE)UP.1943-5444.0000473

Zhang, X., Zheng, Y., Sun, L., \& Dai, Q. (2019). Urban Structure,Subway Systemand Housing Price: Evidence from Beijing and Hangzhou, China. Sustainability, 11(3), 669. https://doi.org/10.3390/su11030669 